\title{
Complete sequence and comparative genomic analysis of eight native Pseudomonas syringae plasmids belonging to the pPT23A family
}

José A. Gutiérrez-Barranquero ${ }^{1}$, Francisco M. Cazorla ${ }^{1}$, Antonio de Vicente ${ }^{1}$ and George W. Sundin ${ }^{2^{*}}$

\begin{abstract}
Background: The pPT23A family of plasmids appears to be indigenous to the plant pathogen Pseudomonas syringae and these plasmids are widely distributed and widely transferred among pathovars of $P$. syringae and related species. PPT23A-family plasmids (PFPs) are sources of accessory genes for their hosts that can include genes important for virulence and epiphytic colonization of plant leaf surfaces. The occurrence of repeated sequences including duplicated insertion sequences on PFPs has made obtaining closed plasmid genome sequences difficult. Therefore, our objective was to obtain complete genome sequences from PFPs from divergent $P$. syringae pathovars and also from strains of $P$. syringae pv. syringae isolated from different hosts.
\end{abstract}

Results: The eight plasmids sequenced ranged in length from 61.6 to $73.8 \mathrm{~kb}$ and encoded from 65 to 83 annotated orfs. Virulence genes including type III secretion system effectors were encoded on two plasmids, and one of these, pPt0893-29 from P. syringae pv. tabaci, encoded a wide variety of putative virulence determinants. The PFPs from $P$. syringae pv. syringae mostly encoded genes of importance to ecological fitness including the rulAB determinant conferring tolerance to ultraviolet radiation. Heavy metal resistance genes encoding resistance to copper and arsenic were also present in a few plasmids. The discovery of part of the chromosomal genomic island Gl6 from P. syringae pv. syringae B728a in two PFPs from two P. syringae pv. syringae hosts is further evidence of past intergenetic transfers between plasmid and chromosomal DNA. Phylogenetic analyses also revealed new subgroups of the pPT23A plasmid family and confirmed that plasmid phylogeny is incongruent with P. syringae pathovar or host of isolation. In addition, conserved genes among seven sequenced plasmids within the same phylogenetic group were limited to plasmid-specific functions including maintenance and transfer functions.

Conclusions: Our sequence analysis further revealed that PFPs from $P$. syringae encode suites of accessory genes that are selected at species (universal distribution), pathovar (interpathovar distribution), and population levels (intrapathovar distribution). The conservation of type IV secretion systems encoding conjugation functions also presumably contributes to the distribution of these plasmids within $P$. syringae populations.

Keywords: Copper resistance, rulAB, hopBD1, Plasmid phylogeny, P. syringae, Genomic island

\footnotetext{
* Correspondence: sundin@msu.edu

2Department of Plant, Soil, and Microbial Sciences, Michigan State University,

East Lansing, MI 48824, USA

Full list of author information is available at the end of the article
}

(c) The Author(s). 2017 Open Access This article is distributed under the terms of the Creative Commons Attribution 4.0 International License (http://creativecommons.org/licenses/by/4.0/, which permits unrestricted use, distribution, and reproduction in any medium, provided you give appropriate credit to the original author(s) and the source, provide a link to the Creative Commons license, and indicate if changes were made. The Creative Commons Public Domain Dedication waiver (http://creativecommons.org/publicdomain/zero/1.0/) applies to the data made available in this article, unless otherwise stated. 


\section{Background}

Pseudomonas syringae is a widely-studied plantpathogenic bacterium of interest as a model for analysis of the molecular bases of host-pathogen interactions and of epiphytic growth on plant leaf surfaces. This species can be subdivided into over 60 pathological variants or pathovars that are mainly distinguished by host range [1]. Phylogenetic and taxonomic analyses of the P. syringae species have demonstrated that the species is grouped into four clades with some former pathovars such as $P$. cannabina and $P$. savastanoi re-elevated into separate species with their own subsets of pathovars $[2,3]$. Genetic and genomic analyses of host range differentiation among $P$. syringae pathovars typically focus on differences in the repertoire of specific type III effector proteins $[4,5]$. The type III secretion system (T3SS) is required for $P$. syringae pathogenesis and encodes a specialized delivery system functioning in the translocation of effector proteins directly into the cytoplasm of plant cells. Type III effectors function collectively to suppress plant defenses and to establish infections that result in plant cell death and release of nutrients to invading pathogen cells [6-8]. Genome sequence evidence indicates that many type III effector genes were acquired via horizontal gene transfer; in addition, the location of many of these genes adjacent to mobile genetic elements facilitates their transfer to and relocation within genomes [5, 9-11].

Plasmids are critical sources for evolution due to their capacity to acquire foreign DNA sequences and to their ability to affect their transfer among bacteria via selfencoded mechanisms such as conjugation and mobilization [12]. Plasmids are viewed as major contributors to genome innovation and in many cases represent the first acquisition point for foreign DNA sequences into a cell. Plasmid sequences comprise a significant portion of the variable genome (also known as the accessory or flexible genome), that portion of the genome that does not encode basic survival functions but instead contributes to ecological fitness in specific habitats, lifestyles, or environmental conditions [13-15]. Bacterial plasmids tend to encode more mobile genetic elements than chromosomes, and undergo recombination at higher frequencies than chromosomes [16, 17]. These facets of plasmid biology, along with the dispensability of plasmids to organism survival, empower plasmids as breeding grounds for the evolution of novel genetic determinants and for the distribution of these genes within a communal gene pool $[12,18]$.

The pPT23A plasmid family comprises a group of plasmids that appear to be indigenous to $P$. syringae and related organisms. pPT23A-family plasmids (PFPs) typically range from 35 to $100 \mathrm{~kb}$ and share a conserved major replication gene repA and origin of replication
$[19,20]$. The gene content of PFPs encompasses genes encoding plasmid-specific functions, including two distinct gene sets encoding type IV secretion systems $\left(\mathrm{MPF}_{\mathrm{T}}\right.$ and $\mathrm{MPF}_{\mathrm{I}}$ of the eight different classes recently identified [21, 22]) specifying conjugation functions, and a variety of other genes either experimentally shown to or postulated to confer virulence or ecological fitness traits [15]. Sequence and hybridization analyses have shown that individual PFPs can encode genes that are distributed at population, pathovar, or species-specific levels [21, 23-25]. Horizontal gene transfer has played a significant role in the evolution of PFPs; for example, a phylogenetic analysis demonstrated that PFPs were widely transferred among $P$. syringae pathovar hosts and that individual genes had been transferred among distinct PFPs [26]. PFPs have also acted as a repository for the acquisition of bactericide-resistance genes including copper resistance determinants and the streptomycinresistance transposon Tn5393 [27-29].

To date, closed genomic sequences of twelve PFPs are available from $P$. syringae pathovars phaseolicola, maculicola, syringae, tomato and actinidiae, $P$. cannabina pathovar (pv.) alisalensis, and P. savastanoi pv. savastanoi [3, 23, 25, 30-35]. However, acquisition of closed plasmid sequences has been difficult due to the presence of multiple repeated insertion sequence elements on some of these plasmids and due to the presence of multiple PFPs in many P. syringae strains [25]. Draft sequences of various $P$. syringae genomes are becoming available at a faster and faster rate [5, 35-39]. Unfortunately, the presence of plasmids and especially of PFPs in these genomes and an examination of their gene content is lacking. For example, in a comparative genomics study of $P$. syringae pathovars, it was noted that it was "difficult to truly identify presence of plasmids using short-read assembly information alone" [5]. In fact, we only found one $P$. syringae genomics study with significant information on plasmid genome content; results from this study indicated that most of the strain-specific genes identified in $P$. savastanoi pv. glycinea strains were located within plasmid DNA sequences [36].

We hypothesized that further understanding of the evolution of the pPT23A plasmid family and the role of these plasmids in P. syringae biology and pathogenesis required the determination and analysis of additional complete, closed plasmid genome sequences. Thus, in this work we sequenced eight PFPs and performed comprehensive bioinformatic analyses of these plasmids.

\section{Results}

Complete closed native plasmid sequences analysis

It is well known that the majority of strains belonging to the $P$. syringae group can harbor at least one indigenous plasmid $[39,40]$, although the number of harbored PFP 
plasmids can vary $[19,24,25]$. In addition, PFPs have been shown to share a large amount of repeated sequences including insertion sequence elements [41]. These two facts can constitute a relevant bottleneck during plasmid isolation and sequencing $[5,25]$.

In light of the above mentioned potential problems, we selected eight different $P$. syringae strains for this study that were previously identified as harboring only one plasmid, in order to facilitate plasmid isolation and the subsequent sequencing process. Thus, the complete closed sequences of eight different plasmids isolated from eight different $P$. syringae bacterial strains belonging to three pathovars were obtained (Table 1). Six of the eight plasmids were obtained from strains of the pathovar syringae isolated from diseased mango trees $(n=4)$, sweet cherry $(n=1)$, and ornamental pear $(n=1)$. One plasmid was obtained from the pathovar garcae isolated from coffee, and the remaining plasmid was obtained from the pathovar tabaci isolated from tobacco. All of the plasmids analyzed in this study were previously identified to be PFPs because they share the essential replication protein RepA [15, 19]. After plasmid isolation and purification using $\mathrm{CsCl}$-Ethidium bromide gradients, sequencing was carried out using the Roche 454 GS (FLX procedure) platform with paired-end reads. Pass filter reads (PF reads) ranged from 42,807 of pPg2708 to 119,949 of pPs1029, and the mean read length ranged from 249 of pPs6-9 to 335 of pPs0158. Contigs generated for the majority of plasmids were 1 with the exception of pPg2708 plasmid that were 2. In order to verify if the sequencing and subsequent assembly process were reliable, two different test methods were carried out. Firstly, a PCR analysis using specific primers (Additional file 1: Table S1, Additional file 2: Figure S1) designed on the plasmid initial and final raw sequences revealed that the 454 sequencing platform

Table 1 Pseudomonas syringae strains used in this study

\begin{tabular}{clll}
\hline P. syringae & Origin & Host & Reference or source \\
\hline pv. syringae & & & \\
UMAF0081 & Spain & Mango & 28 \\
UMAF0170 & Spain & Mango & 28 \\
UMAF0158 & Spain & Mango & 28 \\
UMAF1029 & Spain & Mango & 28 \\
6-9 & USA & Sweet Cherry & 89 \\
7B44 & USA & Ornamental Pear & 43 \\
Pv. garcae & & & \\
2708 & Africa & Coffee & NCPPB $^{\text {a }}$ \\
Pv. tabaci & & & \\
0893-29 & Hungary & Tobacco & 43 \\
\hline
\end{tabular}

${ }^{\mathrm{a}}$ NCPPB, National Collection of Plant Pathogenic Bacteria (United Kingdom) properly provided the closed circular plasmid sequences. Second, the complete sequence of the plasmid pPs0158 obtained by two different sequencing platforms was compared using the BLAST 2 sequences tool from NCBI (last revision November 2016). This nucleotide comparison showed that the plasmid sequences were identical (data not shown), and thus, validated the sequencing method used in this study.

The main characteristics of the different plasmids sequenced in this study and their genetic maps are summarized in Table 2 and Fig. 1 respectively. The full length closed circular DNA sequences ranged from $61,606 \mathrm{bp}$ of pPs0081 and pPs6-9 plasmids, to 73,842 bp of the pPt0893-29 plasmid and the \%GC content varied from $53.5 \%$ of the plasmid pPg2708, to $56.0 \%$ of the pPt0893-29 plasmid. Annotation methods revealed that the number of ORFs presented in the different plasmids ranged from 65 to 83, and the percentage of hypothetical proteins present in each plasmid ranged from 32.5 to $37.3 \%$. To assign putative functions to the ORFs predicted in each different plasmid, the sequence of each one was compared with the GenBank database using BLASTx searches showing the homology to previously known gene sequences (Additional file 3: Tables S2-S9). The putative function of the different ORFs and their representations in genetic maps (Fig. 1) indicated the presence of common and different genes between all the plasmids. Using the multiple genome alignment software MAUVE, we determined that the synteny of six (pPs0081, pPs0170, pPs6-9, pPs0158, pPs1029 and pPs7B44) of the eight plasmids was very high (Additional file 4: Figure S2). The pPg2708 plasmid had some differences showing some rearrangement events, although this plasmid did share the type IVA secretion system $\left(\mathrm{MPF}_{\mathrm{T}}\right.$, new classification [22]) and some genes related with maintenance and conjugation functions with the other six plasmids analyzed. The highest difference was shown by the pPt0893-29 plasmid; apart from some rearrangement events in comparison with the other plasmids, this plasmid carried the type IVB secretion system $\left(\mathrm{MPF}_{\mathrm{I}}\right.$, new classification [22]). Interestingly, the physical co-localization of both different type IV systems was almost identical in all the plasmid sequences. Schematic representation of the type IV $\mathrm{MPF}_{\mathrm{T}}$ and type IV $\mathrm{MPF}_{\mathrm{I}}$ secretion systems from the sequenced plasmids, showed that they were practically identical to the type IV $\mathrm{MPF}_{\mathrm{T}}$ system from the plasmid pPSR1 from $P$. syringae pv. syringae A2 and with the type IV $\mathrm{MPF}_{\mathrm{I}}$ system from the plasmid DC3000A from $P$. syringae pv. tomato DC3000, respectively (Additional file 5: Figure S3). Small differences could be identified only based on the presence or absence of some hypothetical proteins among the complete set of type IV genes.

Nucleotide comparisons of the eight native plasmids revealed that pPs0081 and pPs6-9 were identical, although 
Table 2 Main characteristics of native plasmids sequenced in this study

\begin{tabular}{|c|c|c|c|c|c|c|c|c|}
\hline P. syringae strains & Plasmid name & Plasmid size (bp) & copABCD & $r u l A B$ & Type IVSS & $\%$ GC content & $n^{\circ}$ of ORF's & $H p\left(n^{\circ}-\%\right)^{a}$ \\
\hline \multicolumn{9}{|l|}{ pv. syringae } \\
\hline UMAF0081 & pPs0081 & 61,606 & $+^{c}$ & $+^{c}$ & IVA (virB genes) ${ }^{c}$ & 55.52 & 66 & $23-34.8$ \\
\hline UMAF0170 & pPs0170 & 64,559 & $+^{c}$ & $+^{c}$ & IVA (virB genes) & 54.90 & 75 & $27-36.0$ \\
\hline UMAF0158 & pPs0158 & 63,004 & $-c$ & + & IVA (virB genes) & 54.58 & 65 & $22-33.8$ \\
\hline UMAF1029 & pPs1029 & 63,013 & $-c$ & + & IVA (virB genes) & 54.59 & 65 & $22-33.8$ \\
\hline $6-9$ & pPs6-9 & 61,606 & $t^{c}$ & + & IVA (virB genes) & 55.52 & 66 & $23-34.8$ \\
\hline 7B44 & pPs7B44 & 71,783 & $+^{c}$ & + & IVA (virB genes) & 54.97 & 83 & $27-32.5$ \\
\hline \multicolumn{9}{|l|}{ pv. garcae } \\
\hline 2708 & pPg2708 & 72,672 & $-c$ & $+^{b}$ & IVA (virB genes) & 53.47 & 83 & $31-37.3$ \\
\hline \multicolumn{9}{|l|}{ pv. tabaci } \\
\hline 0893-29 & pPt0893-29 & 73,842 & $-c$ & $+^{c}$ & IVB (tra genes) & 56.01 & 81 & $29-35.8$ \\
\hline
\end{tabular}

${ }^{\mathrm{a}} \mathrm{Hp}$, number and percentage of hypothetical protein (number of hypothetical proteins divided by total number of proteins) present in each plasmid

${ }^{b}$ The $r u l A$ and rulB genes are located in different positions in the plasmid sequence and in different orientations

' Phenotypic analyses performed previously of highlighted plasmids have demonstrated copper resistance (CopABCD), UV radiation tolerance (rulAB), and conjugation transfer (virB genes) $[28,29,43,88,45,89]$

both were isolated from different plant hosts and from different continents. In addition, pPs0158 and pPs1029 showed few nucleotide sequence differences, being considered virtually identical plasmids. When the sequences from pPs0170 and pPs7B44 were compared (Additional file 6: Figure S4), both plasmids contained a portion of the genomic island GI6 from P. syringae pv. syringae B728a (marked in grey and with dotted green lines), with the difference that pPs7B44 also harbored an operon involved in arsenic resistance (purple arrows), that is present in the GI6 genomic island but missing from pPs0170.

\section{Comparative analysis of PFP gene content}

Many PFPs from $P$. syringae strains have been described previously to improve the epiphytic fitness of their hosts. For example, the rulAB operon that functions in DNA repair, confers UV radiation tolerance and contributes to $P$. syringae survival on leaf surfaces [41-44]. The characteristic rulAB operon was identified in seven of the eight plasmids sequenced in this study. In the pPg2708 plasmid, the rulA gene is present in the same location and orientation compared to the other plasmids, but the rulB gene appeared nicked and the two different fragments (one very small, 36 amino acids encoded in the $\mathrm{N}$ terminal region) were located in different positions and in different orientations into the plasmid. Among these two rulB fragments, we have found an insertion of DNA of approximately $36.5 \mathrm{Kbp}$ that harbors 4 different effectors of the T3SS (Fig. 2a).

Furthermore, in order to decipher if these genes could be putatively functional, the presence of the promoter and Shine-Dalgarno sequences were bioinfomatically sought for rulA and for the largest fragment of rulB (Fig. 2b). Promoter regions were determined for both
rulA and rulB, but a Shine-Dalgarno sequence was only found for the rulA gene.

Other important features commonly associated with PFPs that improve the epiphytic fitness of $P$. syringae in agricultural ecosystems are the copper resistance genes $[28,45]$. Although normally copper resistance genes appear forming the cop $A B C D$ operon in $P$. syringae, different genetic structures have also been observed and characterized for their role in improving copper resistance [29]. Two of the eight plasmids sequenced in this study (pPs0170 and pPs7B44) encoded the common copABCDRS operon, and a small metal binding protein that is slightly different in sizes between these two plasmids and that has not been previously described associated with this operon in plasmids. Two other plasmids (pPs0081 and pPs6-9) contained a novel genetic structure with the $\operatorname{cusCBA}$ operon, a $\operatorname{cop} G$ gene, a copper chaperone, and a copper transcriptional regulator inserted into the copABCDRS operon; these determinants are related with the detoxification of monovalent cations (Fig. 1).

Plasmid conjugation has been described to be encoded by the type IV secretion system, and is the main mechanism for gene transfer among phytopathogenic bacteria [46]. It was noteworthy that some specific genes not observed previously in other plasmids forming a characteristic structure have been identified in seven of the eight plasmid sequences (not found in pPt0893-29). These genes were located upstream of the type IV MPF ${ }_{T}$ secretion system genes and were delimited by a phage integrase. The arrangement of these genes was the following: 1) a luxR transcriptional regulator 2) an $A B C$ transporter substrate-binding protein, factor, 3) a $X R E /$ $P b s x$ transcriptional regulator, 4) a NusG transcriptional 


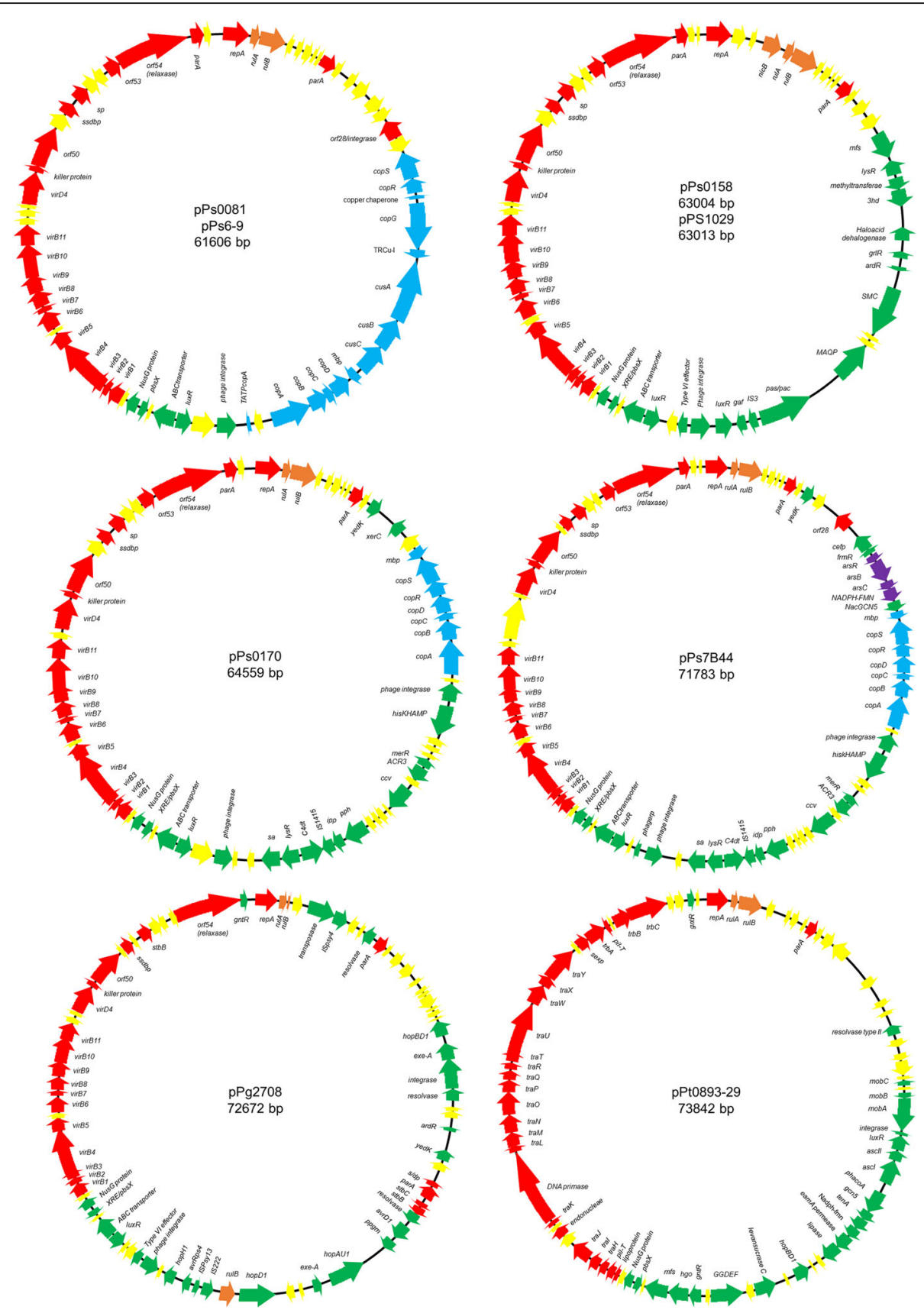

Fig. 1 Circular genetic maps of pPs0081, pPs0170, pPs0158, pPs1029, pPs6-9, pPs7B44, pPg2708 and pPt0893-29 plasmids. repA is defined as the ORF1 in all plasmids analysis in this study. ORFs are color-coded according to their putative functions. ORFs involved in replication, stability and conjugation functions are colored in red. ORFs involved in epiphytic fitness and P. syringae host-interactions are colored in green. ORFs involved in copper detoxification are colored in blue. ORFs involved in arsenic detoxification are colored in purple. The rulAB operon is colored in orange. ORFs predicted as hypothetical proteins are colored in yellow. Putative directions of transcription of each ORF, are indicated by an arrow. The identity of each ORF is given inside the plasmid circular map, with the exception of the hypothetical proteins. Plasmids maps are not drawn at scale

regulator-termination protein, and then, the type IV $\mathrm{MPF}_{\mathrm{T}}$ secretion system (Fig. 1).

Finally, PFP sequences have also been related with virulence function, mainly through encoding T3SS effectors and toxin genes $[15,23,25,32,38]$. In this study, type III effectors were identified bioinfomatically in two plasmids (pPg2708 and pPt0893-29). The pPt0893-29 plasmid harbored the effector hopBD1 that was also shared with the pPg2708 plasmid. Blast 2 sequence comparison revealed query coverage of $100 \%$, with an 


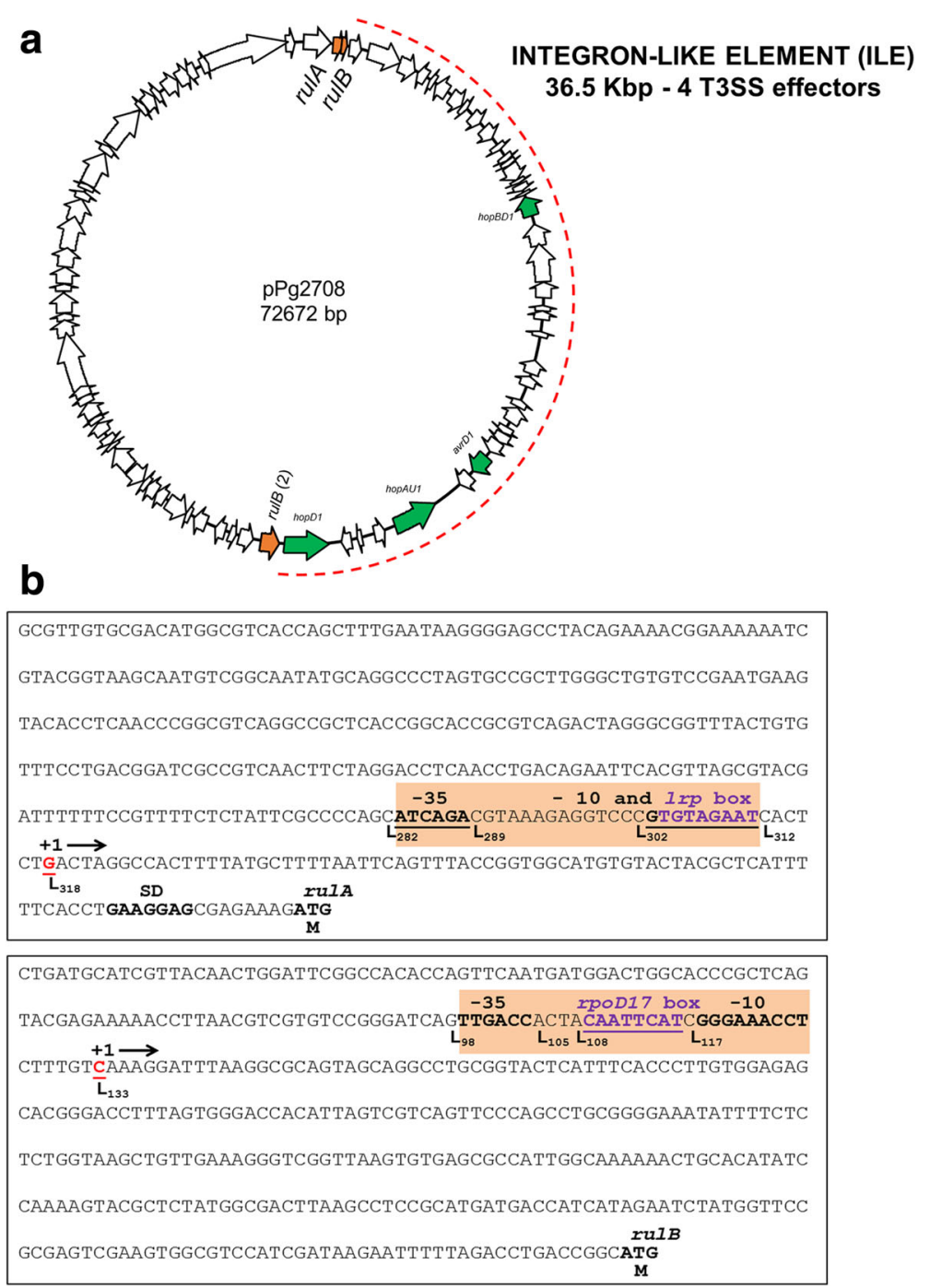

Fig. 2 rulAB DNA region analysis of pPg2708. a Plasmid map of pPg2708 with the location of rulA and rulB nicked genes, marked in light orange. INTEGRON-LIKE ELEMENT (ILE) OF $36.5 \mathrm{Kbp}$ among the rulB nicked gene marked with dotted red line. Four putative type III effectors are marked in green color. $\mathbf{b}$ Representation of the non-coding region of the rulA and the big part of rulB genes which contains the putative promoter sequences. The nucleotide sequences of both putative promoters (indicated in light orange) showing the proposed -10 box, -35 box and the TF binding sites; the nucleotide position is also indicated. The putative Shine-Dalgarno sequence was only found for the rulA gene, and is shown in bold type

identity of $97 \%$ (data not shown). The effector hopBD1 and five others present in pPg2708 were characterized further in order to predict in silico their functionality (Table 3). Bioinformatic predictions based on the presence of signal peptide, transmembrane domain, and the detection of $h r p$-boxes ( $h r p$-boxes are cis-elements shared in the promoter regions of genes encoding T3SS and type III effectors) within promoter sequences showed that five of the six putative type III effectors predicted originally in pPG2708, could be functional and thus, play an important role in virulence. In addition, the vast amount of hypothetical proteins present on the different plasmids were analyzed to determine their putative role as effectors of the T3SS (Table 4).
Bioinformatic predictions based on the presence of signal peptide, transmembrane domain, and amino acid sequences using the Effective T3 tool, suggested that at least 8 hypothetical proteins could potentially function as type III effectors. One hypothetical protein was found in pPs0170, one in pPs7B44, and three in both pPg2708 and pPt0893-29 (Table 4).

Pseudomonas syringae PFPs have been also demonstrated to encode other Hrp-independent virulence factors such as enzymes for phytohormone biosynthesis, which are also encoded in plasmids from other plant pathogens [25, 47]. pPt0893-29 is the unique plasmid from this study that encoded other potential virulence genes such as anthranilate synthase I and II, involved in 
Table 3 Bioinformatic predictions of main characteristics of putative type III effector proteins found in pPg2708 plasmid

\begin{tabular}{lllll}
\hline Putative type III effectors & Size (aa) & Signal peptide & T. domains & Hrp-box $^{\text {a }}$ \\
\hline AvrD1 & 311 & $32-44$ & ND & ggaaccaaatccgtcccaaaggccacaca \\
AvrRps4 & 228 & ND & ND & ND \\
HopAU1 & 731 & $30-42$ & ND & ggaaccctcctgtgattttcgaacactca \\
HopBD1 & 300 & $110-122$ & ND & ggaaccgatcgaggggttctgaccacata \\
HopD1 & 713 & $45-57$ & ND & ggaacccaagagcccttgcgaccacaca \\
HopH1 & 218 & $12-24$ & ND & ggaactatcctcccacacgaagccactta \\
\hline
\end{tabular}

a Transmembrane domains

${ }^{b}$ Hrp-box is a cis promoter element recognized by the alternate sigma factor HrpL and is associated mainly with genes encoded in the type III secretion system of plant pathogenic bacteria

c Non-detected

tryptophan synthesis, levansucrase $\mathrm{C}$ related with the synthesis of levan, and finally a diguanylate cyclase (GGDEF) potentially involved in cyclic di-GMP synthesis, a second messenger compound that is involved in virulence of plant and opportunistic human Pseudomonas spp. pathogens and other plant pathogens $[48-51]$.

\section{Phylogenetic analysis redefined the evolutionary history of pPT23A family plasmids}

In order to unravel the evolutionary history of the $P$. syringae PFPs, a phylogenetic analysis using 47 rep $A$ gene sequences from different $P$. syringae plasmids present in the NCBI database and the repA sequences from the eight plasmids sequenced in this study was performed. This phylogenetic analysis was conducted using two different methods: 1) using as the outgroup the repA sequences of two plasmids from Xanthomonas citri pv. citri A306 (Fig. 3a), and 2) not using an outgroup (Fig. 3b). Phylogenetic analysis using the repA outgroup sequences revealed the presence of four evolutionary groups as previously described (Groups A, B, C and D; [26]), and the presence of a new group of plasmids designated as group " $E$ " that was phylogenetically closely related with group A (Fig. 3a). This new group E, was comprised of plasmids previously characterized in group A; pPt0893-29 sequenced in this study was also included in this new group (highlighted with a black box). The remaining seven plasmids sequenced in this study were grouped together, forming part of the already known group B (Fig. 3a, highlighted with a black box). Phylogenetic analysis carried out without the use of the outgroup sequences, showed the presence of two new groups "E" and "F", that were basically composed of the

Table 4 Hypothetical proteins predicted as bacterial secreted effector proteins. Detection of signal peptides, transmembrane domains and sequence based prediction

\begin{tabular}{|c|c|c|c|c|c|}
\hline H. proteins ${ }^{a}$ & $\begin{array}{l}\text { Protein size } \\
\text { (aa) }\end{array}$ & $\begin{array}{l}\text { Signal peptide } \\
\text { (from-to) }\end{array}$ & $\begin{array}{l}\text { Trans. domains } \\
\text { (from-to) }\end{array}$ & $\begin{array}{l}\text { Type III effector prediction } \\
\text { with standard set }\end{array}$ & $\begin{array}{l}\text { Type III effector prediction } \\
\text { with plant set }{ }^{c}\end{array}$ \\
\hline \multicolumn{6}{|l|}{ pPs0170 } \\
\hline Hp11 & 79 & $1(34-46)$ & $N D^{d}$ & 0.99817 & $N P^{e}$ \\
\hline \multicolumn{6}{|l|}{ pPs7B44 } \\
\hline Hp6 & 191 & $1(26-38)$ & ND & 0.94647 & NP \\
\hline \multicolumn{6}{|l|}{ pPg2708 } \\
\hline Hp10 & 242 & $1(55-67)$ & ND & 0.99997 & 1 \\
\hline Hp18 & 160 & $1(14-26)$ & ND & 0.99922 & 1 \\
\hline Hp27 & 94 & $1(7-19)$ & ND & 0.99988 & 0.99994 \\
\hline \multicolumn{6}{|l|}{ pPt0893-29 } \\
\hline Hp4 & 66 & $1(1-9)$ & ND & 0.99903 & 0.9804 \\
\hline Hp14 & 62 & $1(1-8)$ & ND & 0.99447 & $N P$ \\
\hline Hp27 & 140 & $1(60-72)$ & ND & NP & 0.99798 \\
\hline
\end{tabular}

\footnotetext{
${ }^{a}$ Hypothetical proteins that meet the three requirements, in all the plasmids analyzed

b Standard classification module: comprises effectors of Escherichia coli, Salmonella, Chlamydia, Yersinia, and Pseudomonas

c Plant classification module: comprises effector sequences from Pseudomonas syringae

${ }^{\mathrm{d}} N D$ Non-detected

e NP Non-predicted
} 


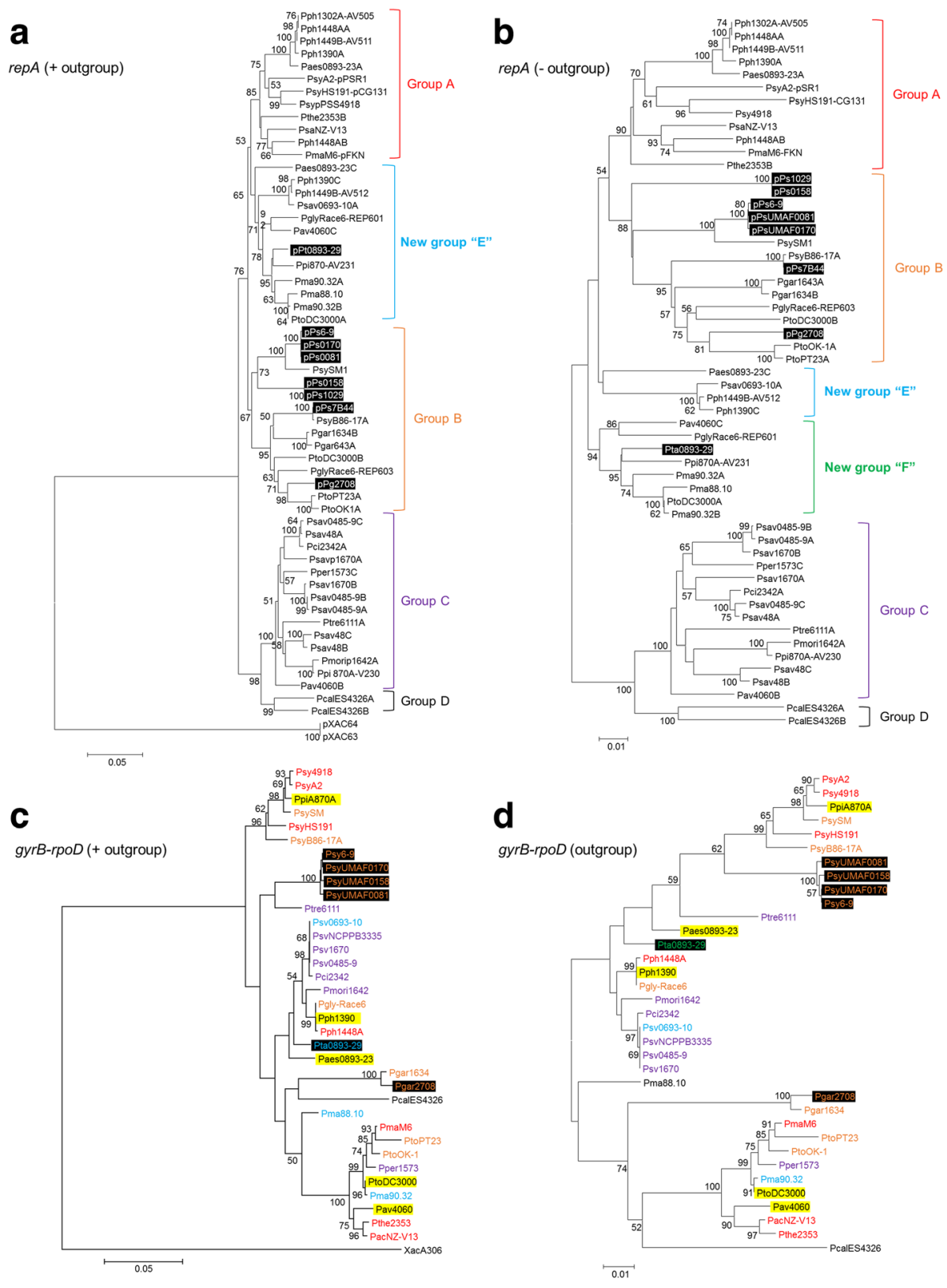

Fig. 3 Evolutionary history of PPT23A family plasmid and their Pseudomonas syringae and related Pseudomonas hosts. a Phylogenetic analysis of the complete repA sequences of PPT23A family plasmids from Pseudomonas syringae and related strains, using as the outgroup the repA sequences of two plasmids (p33 and p64) from Xanthomonas citri pv. citri A306. b Phylogenetic analysis using the repA sequences from Pseudomonas syringae plasmids, not including in this tree the outgroup plasmids. c Phylogeny of Pseudomonas syringae and related strains harboring plasmids from the pPT23A family was constructed based on the analysis of two concatenated housekeeping genes (gyrB and rpoD), using as the outgroup the gyrB-rpoD sequences from Xanthomonas citri pv. citri A306. d Phylogenetic analysis using the concatenated housekeeping genes (gyrB and rpoD) from Pseudomonas syringae and related strains, not including in this tree the outgroup strain. The neighbor-joining tree was constructed by MEGA 5 using the JukesCantor model. Percent bootstrap values of more than 50\% (1000 repetitions) are shown at the nodes. The topology of the different trees, was identical by using the minimum evolution and maximum parsimony methods. Gray boxes: the outgroup plasmids and strain. Black boxes: plasmids sequenced in this study. Yellow Boxes: corresponding with P. syringae strains that harbor two pPT23A plasmids, with each plasmid belonging to a different evolutionary cluster

plasmids belonging to the new group E described above (Fig. 3b), although the bootstrap value for the new group E was lower than 50 . In addition, these two new groups were more distantly related with group A of plasmids, in comparison with the previous phylogeny obtained using the outgroup sequences.

The trees generated with the repA sequences were then compared to those derived from a multilocus 
sequence analysis using partial sequences of $\operatorname{gyr} B$ and $r p o D$ genes obtained from the database for some of the $P$. syringae strains included in the repA phylogeny, in order to evaluate the association of specific plasmids with specific host chromosomal genotypes. The phylogenetic groups generated were practically identical irrespective of using or not using outgroup sequences (Fig. 3c and d). Following the color scale, we could observe how the evolutionary history of PFPs and their bacterial hosts was incongruent. The $P$. syringae pv. syringae strains isolated from mango (UMAF0081, 0158 and 0170) along with the strain isolated from sweet cherry, formed a unique cluster. $P$. syringae pv. garcae 2708, grouped together with the other pv. garcae strain included in this study, and $P$. syringae pv. tabaci 0893-29 was grouped together with different pathovars of $P$. syringae ( $\mathrm{pv}$. aesculi, pv. phaseolicola, pv. glycinea, etc.).

In order to gain a greater understanding with respect to the evolutionary history of the pPT23A family, and how these plasmids could play a major role in P. syringae biology, the phylogenetic distribution based on the repA sequences (of those plasmids with complete sequences available) and its relationship with the host of isolation, and with other important genetic features of plasmids of this family (copper and UV resistance, and the presence of type IV secretion system) was analyzed (Fig. 4a). A total of 22 repA sequences were used for this purpose. From this analysis, we observed the presence of the original four groups, and the presence of one new group formed by pPtDC3000A from $P$. syringae pv. tomato, and by the pPt0893-29 plasmid from the pv. tabaci, that was sequenced in this study. The rest of the plasmids sequenced in this study were placed in group $\mathrm{B}$, and all of them harbored the rulAB operon and the type IV $\mathrm{MPF}_{\mathrm{T}}$ secretion system. To decipher if there were more genes shared by seven plasmids sequenced in this study that belonged to group B, an analysis of the core genome was carried out by using a Venn diagram analysis (Fig. 4b). This analysis revealed that this subgroup of plasmids share 27 core genes related mainly with maintenance and mobilization functions.

Possibly the most interesting genes regarding plasmidspecific functions revealed by the core genome analysis could be related with the induction or repression of the conjugation system, and were present in seven of eight plasmids sequenced in this study. These genes included a luxR transcriptional regulator, an $A B C$ transporter, a $X R E / p b s x$ transcriptional regulator and a $n u s G$ transcriptional regulator-termination protein; all of them located upstream of the type IV $\mathrm{MPF}_{\mathrm{T}}$ secretion system. Interestingly, the $X R E / p b s x$ transcriptional regulator and the $n u s G$ transcriptional regulator-termination protein are also present upstream of the type IV $\mathrm{MPF}_{\mathrm{I}}$ secretion system of pPt0893-23. A phylogenetic analysis was conducted for these genes independently (Fig. 4a, b, c and d), concatenated (Fig. 5e), and also using 27 concatenated core genes (Fig. $5 \mathrm{f}$ ) and the complete plasmid sequences (Fig. 5h), from the seven plasmids that harbored the type IV MPF bution showed for the different phylogenetic analysis was similar, and grouped together the plasmids that harbored copper resistance genes (blue); the plasmids that did not encode copper resistance were contained in two separate groups (red). These analyses held for each gene analyzed except nusG (Fig. 5d). Also, this phylogenetic distribution was altered, when the repA phylogeny of the seven plasmids was used (Fig. 5g). Three different groups were observed, plasmids encoding copper resistance genes (blue), plasmids not harboring copper resistance genes (red), and another group with both copper resistance and copper sensitive plasmids (purple). This altered phylogenetic distribution was not observed when the analysis was conducted using the 27 core genes and the complete plasmid sequences (Fig. $5 \mathrm{f}$ and $\mathrm{h}$ ).

\section{Discussion}

We report the complete closed sequence and comparative genomics analysis of eight PFPs from the plant pathogen $P$. syringae. As previously reported, PFPs share the major replication gene $\operatorname{rep} A[15,19]$; this major replication gene is the only gene currently known to be distributed among all plasmids of the pPT23A family. The pPT23A plasmid family is ubiquitous but not universal within the species $P$. syringae, as there have been strains isolated that do not contain any plasmids. However, most $P$. syringae strains studied contain one or multiple PFPs; a unique feature of the pPT23A family is the coexistence of two to several PFPs within individual P. syringae strains. The origin of multiple PFPs within individuals may be through incremental acquisition of plasmids or through plasmid duplication events $[25,26]$. The compatibility of multiple PFPs within the same host cell was originally hypothesized to be due to alterations in amino acid sequence at the C-terminus of RepA [15]. However, more recent evidence has suggested that a putative control region sequence consisting of stemloop structures upstream of repA enables compatibility of PFPs if the sequence differs by only a few nucleotides [52].

A previous phylogenetic analysis of PFPs indicated incongruence between PFP phylogeny and host $P$. syringae pathovar phylogeny [26]. Those results suggested that horizontal transfer had played a role in the current observed distribution of PFPs within $P$. syringae, and that specific plasmid:pathovar relationships did not exist. Experiments performed in vitro have demonstrated conjugative transfer for PFPs, including some instances of 

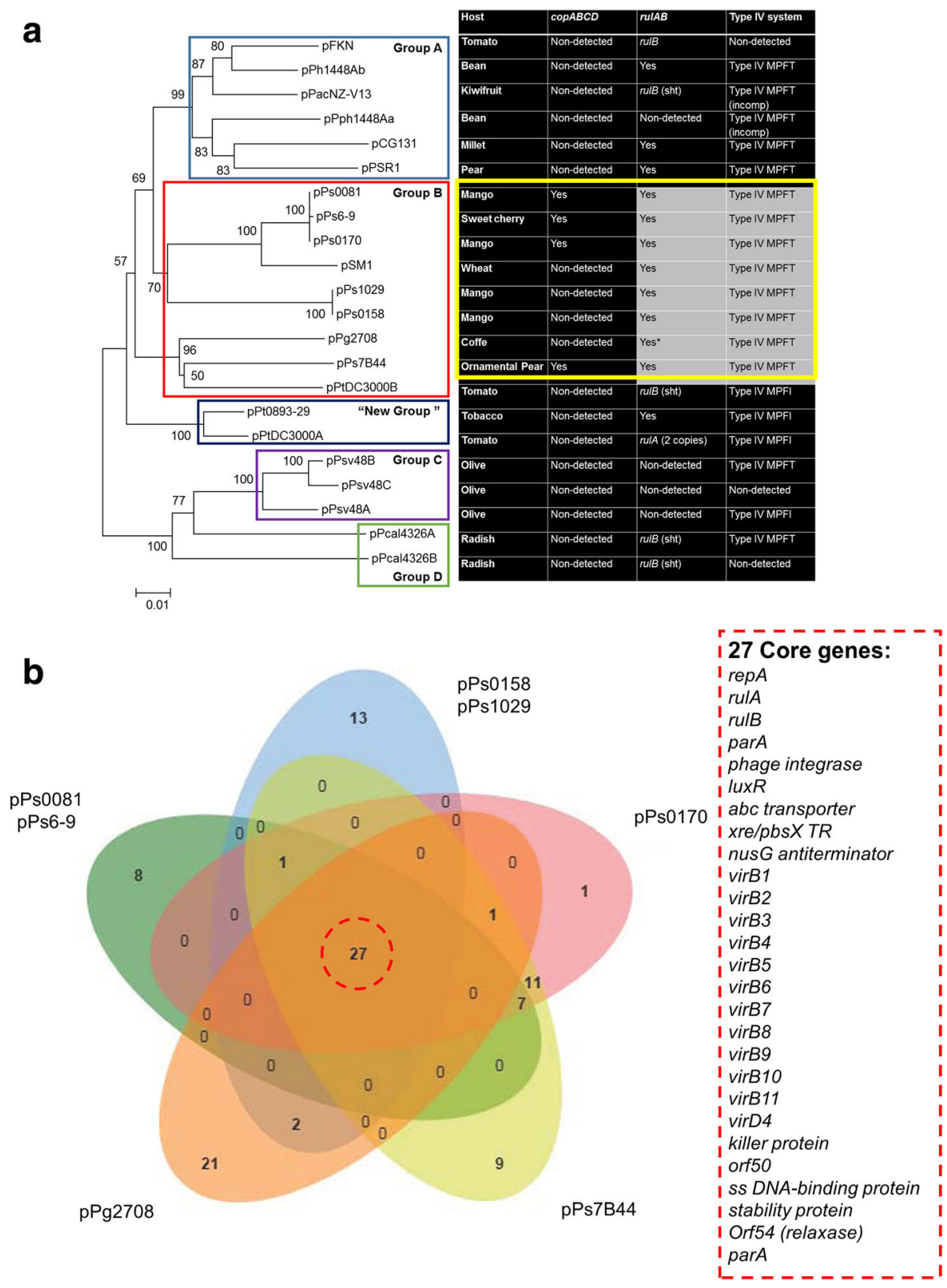

Fig. 4 Phylogenetic relationships predict a new sub cluster into the plasmid group B. a Phylogenetic analysis using the repA sequences only from plasmids, whose their complete sequences are available in the database. The neighbor-joining tree was constructed by MEGA 5 using the JukesCantor model. Bootstrap values (1000 repetitions) are shown at the nodes. The plant host of isolation and the presence of some characteristic genes of the PPT23A family plasmids (such as COPABCD and rulAB operon, and Type IV secretion system) are represented in the right columns beside each plasmid name. sht: sequence shorter than expected; imcomp: incomplete; *: rulA and rulB genes located at different positions and orientations. b Genomic diversity of the sub cluster of plasmids. Each plasmid is represented by an oval. The number of orthologous proteincoding genes shared by all plasmids (i. e., the core genes) is in the centre. Overlapping regions show the number of coding sequences (CDS) conserved only within the specified plasmids. Numbers in the non-overlapping portions of each oval show the number of CDS unique to each plasmid. Hypothetical proteins were not taking into account to this analysis

interpathovar transfer [23, 28, 45]. Our current results including the eight plasmids sequenced in this study and additional recent sequences from other studies confirmed this finding of incongruence of PFPs and P. syringae host pathovars. Furthermore, a phylogenetic analysis using a concatenated set of 27 conserved core pPFP sequences also supported the incongruence of PFPs and individual $P$. syringae pathovars.

The major contribution of PFPs to the ecological fitness and pathogenesis of $P$. syringae is through carriage 


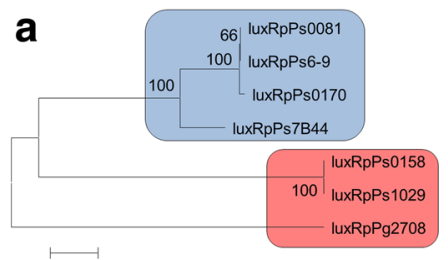

0.02

C

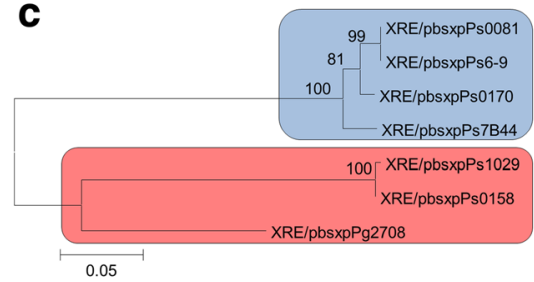

e
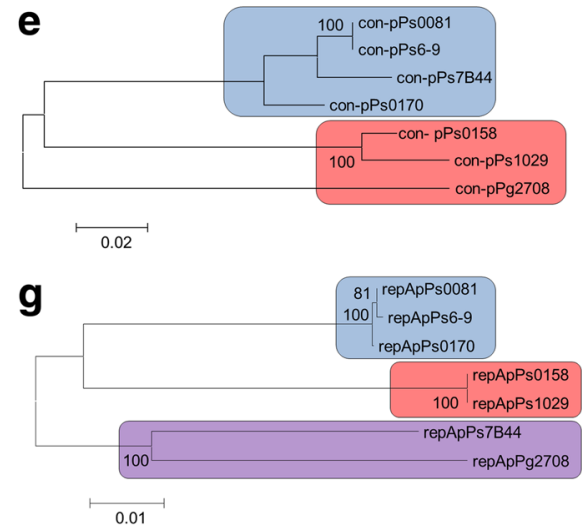

b

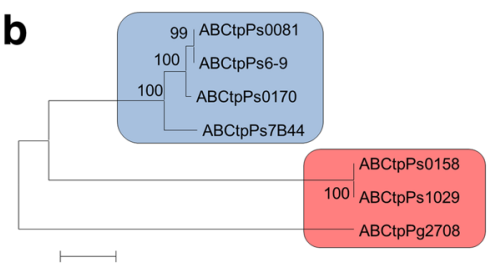

0.02

d

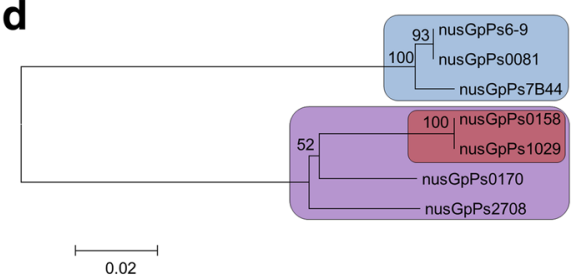

$\mathbf{f}$

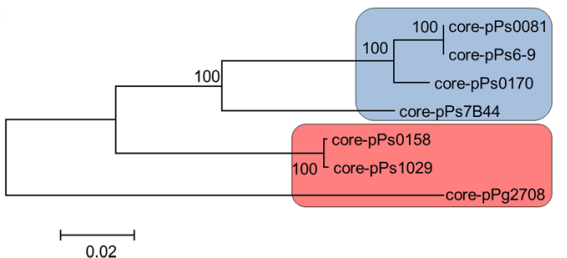

h

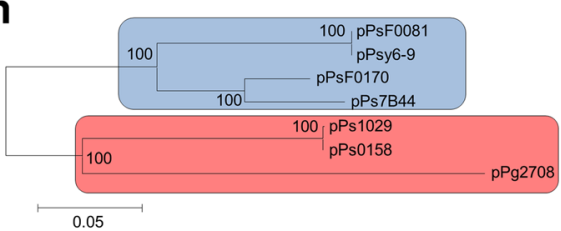

Fig. 5 Phylogenetic distribution of putative signalling-like genes related with the conjugation system. The luxR transcriptional regulator, abc transporter, XRE/pbs X transcriptional regulator and nUSG transcriptional regulator-termination nucleotide sequences from the 7 plasmids of this study that harbor the type IV MPF secretion system, were used independently (a, b, c and $\mathbf{d}$ ) and concatenated (e) to carry out a phylogenetic analysis. In addition, the phylogeny of these plasmids was carried out using the core genes obtained for these plasmids in this study (27 genes) (f), using the repA sequences (g) and analyzing a concatenated dataset containing 27 core plasmid sequences (h). The neighbor-joining tree using the Jukes-Cantor model was generated by MEGA 5. Bootstrap values (1000 repetitions) are show on the branches. Blue box: copper resistance plasmids. Red box: non-copper resistance plasmids. Purple box: copper resistance and non-resistance plasmids

of accessory genes. For example, PFPs may encode any of the following genes including the rulAB genes that confer resistance to ultraviolet radiation, type III effector genes, toxin biosynthesis genes, indole acetic acid biosynthesis genes, levansucrase, and agriculturallyimportant resistance genes to copper or streptomycin [27-29]. The carriage of specific accessory genes on PFPs can be influenced by selection acting at the $P$. syringae species level, with carriage of genes such as rulAB [44]. Other genes such as type III effector genes are likely selected at the pathovar level (i.e., important to a specific $P$. syringae-host interaction), and still others at the population level (i.e., an intrapathovar distribution important in a specific environment). For example, the plasmids pPs6-9 and pPS7B44 (Fig. 1) were isolated from $P$. syringae pv. syringae strains under selection from copper bactericide use on different woody hosts from different regions of the United States. Both of the plasmids encode highly similar backbones with the only major difference being the type of copper resistance determinant acquired which likely reflects the availability of genes within the respective communities.

The PFPs that have been sequenced from $P$. syringae pv. syringae strains in this and other studies have encoded few or no genes encoding type III effectors with potential direct linkages to $P$. syringae-host interactions $[22,34,35]$. This is in contrast to other PFPs, such as pPg2708 and pPt0893-29 in this study, and others that encode multiple type III effectors and additional putative virulence genes [25, 38]. We hypothesize that this is a reflection of the number of effectors required to cause disease and suppress host resistance responses in particular pathosystems; for example, genome sequence analysis of different $P$. syringae pv. syringae strains has shown a relatively small number of type III effectors encoded by these strains [53] compared to other pathovars. Continued acquisition of type III effectors by PFPs may be important in the pathogen-host "arms race" 
positively affecting virulence in other pathovars encoding large effector repertoires. The plasmid pPg2708 from this study presents the rulB gene nicked, and an insertion of $36.5 \mathrm{Kbp}$ of DNA was found, and, carrying among others, 4 type III effectors. The role of rulB gene as a hotspot for site specific insertion of integron-like elements (ILEs) and other putative mobile elements that harbor T3SS effectors among other genes has been previously described $[54,55]$.

We detected large regions from the chromosomallylocated GI6 genomic island of $P$. syringae pv. syringae B728a on two of the PFPs (pPs0170 and pPs7B44) sequenced in this study. This provides further retrospective evidence of the movement of genomic island regions between plasmid and chromosome in P. syringae. The GI6 genomic island shares extensive similarity to the PPHGI-1 genomic island of $P$. syringae pv. phaseolicola $1302 \mathrm{~A}$, a 106-kb genomic island that can excise from the chromosome when strain 1302A is inoculated onto a resistant bean cultivar [56]; however, the copper and arsenic-resistance determinants found on the plasmids sequenced in this study are not present in the PPHGI-1 island. The integration of plasmids into and excision of plasmids from the $P$. syringae chromosome was first demonstrated 35 years ago $[57,58]$. Later, the PFP pFKN was shown to integrate into the chromosome of $P$. syringae pv. maculicola via recombination between alleles of the T3SS effector avrpPhE [31], and the PFP pAV505 of $P$. syringae pv. phaseolicola $1302 \mathrm{~A}$ and two other native plasmids were presumably integrated into the chromosome of the host strain after passage through a resistant bean cultivar [59]. In many cases, these intragenome plasmid recombination or excision events appear to occur as a consequence of host recognition/avoidance scenarios [60]. However, the recombination and relocation of genomic island sequences such as the copper and arsenic-resistance determinants to pPs0170 and pPs7B44 also suggests that other ecological stress selection can play a role in gene movement between plasmids and chromosomes.

The carriage of large plasmids imposes a fitness cost on the host cell that must be ameliorated to enable plasmid maintenance. This coevolutionary process can be mediated through any of several mechanisms including deletion of nonessential sequences from the plasmid, alterations (typically reductions) in plasmid gene expression, and alterations in chromosomal gene expression (reviewed in [61]). The importance of positive selection for plasmid-encoded genes, such as antibiotic-resistance genes, in conjunction with other coevolutionary mechanisms also plays a critical role in plasmid persistence [62]. Conjugative plasmids exhibit a modular structure consisting of discrete gene regions that are clustered into functional groups [12]. These functional groups or modules include replication, stability, propagation, and adaptation with the propagation module including genes functioning in conjugative transfer and the adaptation module including ecologically-important genes [63]. Coordination and co-regulation of genes within these functional modules is also important and contribute to an overall "plasmid survival kit" [63].

Our sequence analysis of PFP genomes in this study illustrated a modular structure of these plasmids (Fig. 1) with replication, stability, propagation, and adaptation modules all present. The ubiquitous nature of PFPs within P. syringae suggests that this plasmid family has successfully coevolved with the $P$. syringae species, however, few studies have assessed the effect of PFPs on the corresponding fitness of the $P$. syringae host $[45,64]$. Co-regulation of the plasmid-selfish genes (replication, stability, propagation modules) likely contributes to a reduction of deleterious effects of PFPs on their P. syringae hosts. Similarities in gene content and synteny of these modules in the plasmids examined in this study and in previous analyses of PFPs genomes [15, 21, 41], suggest that the modules that contribute to the plasmid backbone are strongly conserved.

There is one curious distinction in gene content among the plasmid backbone genes present on PFPs and that involves the composition of the propagation module specifically with regards to conjugative transfer related genes encoding a type IV secretion system (T4SS). There are two known suites of conjugative transfer genes on PFPs, the type IV $\mathrm{MPF}_{\mathrm{T}}-\mathrm{T} 4 \mathrm{SS}$ (VirB-VirD4 conjugative system) and the type IV MPF ${ }^{-}$T4SS (tra conjugative system) [21]. In a previous macroarray study of 31 PFPs from 12 P. syringae pathovars, we identified 12 PFPs that hybridized to most or all of the type IV $\mathrm{MPF}_{\mathrm{T}}-\mathrm{T} 4 \mathrm{SS}$ genes and 10 PFPs that hybridized to all 21 genes of the type IV MPF - T4SS genes [21]. The PFPs that encoded a type IV $\mathrm{MPF}_{\mathrm{T}}-\mathrm{T} 4 \mathrm{SS}$ were distributed among $P$. syringae pathovars in genomospecies I, II, III, and IV, and PFPs that encoded a type IV MPF ${ }^{-}$T4SS were distributed among $P$. syringae pathovars in genomospecies II, III, and IV [21]. Only a few other PFPs were shown to either lack a T4SS or to only hybridize to a few T4SS genes [21]. As shown in the plasmids maps in Fig. 1, the genetic location of either of the type IV $\mathrm{MPF}_{\mathrm{T}}$ or type IV MPF $_{\mathrm{I}}$ T4SSs is very similar, and upstream of the gntR transcriptional regulator, rep $A$, and the rulAB genes, suggesting that both of these T4SS gene sets have been acquired into an existing PFP backbone. In addition, it is not yet clear if carriage of either of the type IV $\mathrm{MPF}_{\mathrm{T}}$ or type IV $\mathrm{MPF}_{\mathrm{I}}-\mathrm{T} 4 \mathrm{SS}$ s is associated with carriage of specific accessory genes including type III effector genes.

Finally, analysis of accessory gene carriage among sequenced plasmids common to gram-negative plant pathogens such as $P$. syringae, Erwinia amylovora, and 
Xanthomonas campestris [15, 65-68] shows a predominance of known and putative virulence determinants and less numbers of genes that may generally enhance fitness in the plant environment. This is in spite of the observation that these plant pathogens do spend parts of their life cycles growing on plant surfaces either on leaves or flowers. Analysis of accessory gene carriage on plasmids isolated from non-pathogenic plant-associated bacteria has shown differing suites of genes compared to those found on plasmids from plant pathogens. For example, pA506, a recently-sequenced plasmid from the plant epiphyte $P$. fluorescens A506, is very similar to PFPs except it does not encode a repA gene or other replication initiation protein [69]. However, although pA506 encodes similar genes in the propagation and stability modules to PFPs and does encode rulAB, there are few other similarities in the accessory gene module [69]. Likewise the pQBR plasmid family which is distributed among bacterial strains isolated from the sugar beet phyllosphere, does not appear to share accessory genes with any other PFPs [70]. Thus, plant pathogens such as $P$. syringae harbor plasmids that encode accessory genes with a plant pathogen "signature" that is important for host-pathogen interactions and/or is selected in response to bactericide usage in agriculture. This suggests in turn that other genes, such as specific epiphytic fitness determinants critical for in planta growth in these pathogens, are maintained as indispensible in chromosomal locations freeing the plasmids to carry genes that, though still dispensible overall to the host bacterium, provide a selective advantage that is strong enough both to maintain the plasmid within the bacterial pathogen population and to maintain the bacterial pathogen populations on their respective plant hosts.

\section{Conclusions}

Our sequence analysis revealed that PFPs from P. syringae encode suites of accessory genes that are selected at species (universal distribution), pathovar (interpathovar distribution), and population levels (intrapathovar distribution), and contribute to ecological and pathogenic fitness. Results from phylogenetic analyses supported the incongruence of PFPs and individual $P$. syringae pathovars, suggesting the importance of horizontal transfer in affecting the current distribution of PFPs in the P. syringae species. The conservation of type IV secretion systems encoding conjugation functions also presumably contributes to the distribution of these plasmids within P. syringae populations.

\section{Methods}

Pseudomonas syringae strains and their native plasmids Pseudomonas syringae strains used in this study are summarized in Table 1. The main characteristics from the different native plasmids isolated from the different $P$. syringae strains and sequenced in this work are described in Table 2. Pseudomonas syringae strains were routinely grown at $28{ }^{\circ} \mathrm{C}$ using Lysogeny (LB) broth and agar medium.

\section{Plasmid DNA Isolation and purification}

Large-scale plasmid DNA extractions were conducted using $1000 \mathrm{~mL}$ LB broth cultures for each strain according to a modified Maxi-preparations (maxi-prep) alkaline lysis method $[66,67]$. The sizes of the different plasmids were estimated based on a control reference strain, $P$. syringae pv. tomato PT23 that harbors four plasmids (pPT23A, pPT23B, pPT23C and pPT23D that are 100$\mathrm{Kb}, 83-\mathrm{Kb}, 65-\mathrm{Kb}$ and $36-\mathrm{Kb}$ in size, respectively) [71]. Subsequently, plasmid DNA purification was carried out by equilibrium centrifugation in cesium chlorideethidium bromide gradients $(\mathrm{CsCl}-\mathrm{EtBr})$ gradients [72] Briefly, each plasmid maxi-prep was resuspended in $8 \mathrm{~mL}$ of TE buffer ( $\mathrm{pH} 8.0)$, and $8.8 \mathrm{~g}$ of $\mathrm{CsCl}$ and $800 \mu \mathrm{L}$ of $\mathrm{EtBr}(10 \mathrm{mg} / \mathrm{mL})$ were added. These gradient preps were subjected to ultracentrifugation $(16 \mathrm{~h}$, $194,000 \times g, 20^{\circ} \mathrm{C}$ ), and then the plasmid DNA was collected using a hypodermic needle and a disposable syringe. Then, the $\mathrm{EtBr}$ and $\mathrm{CsCl}$ were removed from the plasmid DNA extraction [73]. Finally, the plasmid DNA was precipitated and dissolved in $0.5 \mathrm{~mL}$ of TE buffer (pH 8.0).

\section{Plasmids sequencing and annotation}

The complete plasmid DNA sequences were obtained using Roche 454 GS (FLX procedure) platform, and were carried out at the Genomics Technology Support Facility, Michigan State University. DNA sequences for each plasmid were assembled using Newbler Ver2.0 (Roche 454 Life Sciences). In order to validate the sequencing method used in this study, the sequencing of one of the plasmids was also carried out at the Beijing Genomics Institute (BGI-HK) using Illumina HiSeq 2500 system. The plasmid selected for this purpose was the plasmid from $P$. syringae pv. syringae UMAF0158 that has been recently published [74]. Comparative sequence analysis of this plasmid sequenced by different methods was carried out using BLAST 2 Sequences tool from NCBI [75].

The complete sequence from the eight different native plasmids were then placed in the same orientation, taking as nucleotide +1 , the nucleotide +1 of the repA gene. The plasmids were automatically annotated using Rapid Annotations using Subsystems Technology (RAST) [76]. Subsequently, they were manually refined using different tools such as are BLASTx [77] and the graphical analysis tool ORF Finder (http://www.ncbi.nlm.nih.gov/gorf/ gorf.html). The search of open reading frames (ORFs) 
that were detected by BLASTx but not by ORF Finder, including the ORFs with alternative start codons (gtg and ttg) was carried out using Redasoft Visual Cloning 3.2. This software was also used for the construction of the genetic plasmid maps [23]. The last revision of plasmid sequence annotation was done in November 2016.

\section{Molecular biology techniques}

Polymerase chain reaction (PCR) method using specific primers designed on the eight different plasmid DNA sequences (Table S1) was carried out in order to test if the sequencing method used in this study generated correctly closed circular DNA. The PCR was performed between the start and the end of each plasmid using the raw DNA sequences provided by the Genomics Technology Support Facility, Michigan State University.

For this purpose, genomic DNA was extracted by using the DNeasy tissue kit (QIAGEN Inc., USA) according to the manufacturer's instructions. Furthermore, plasmid DNA mini-preparations were performed using $1.5 \mathrm{~mL}$ of an LB broth overnight culture following a modified alkaline lysis method [71]. DNA concentrations and quality from both were determined using NanoDrop ND-1000 (NanoDrop Technologies) spectrophotometer and by agarose gel electrophoresis.

\section{Bioinformatic analysis Phylogenetic studies}

A phylogenetic analysis using the repA gene sequences of the eight plasmids sequenced in this study, and also including other repA sequences present in the NCBI database that belong to other plasmids from the same family (pPT23A) was conducted. In addition, an evolutionary history study based on the analysis of the $g y B$ and rpoD housekeeping genes of the Pseudomonas syringae and related Pseudomonas whose harbor the pPT23A plasmids was carried out. The different DNA sequences were alignment using Clustal W2 [78] and the different phylogenetic trees were generated using MEGA 5 [79] with neighbor-joining, Jukes-Cantor model, minimum evolution, and the option of complete deletion to eliminate positions containing gaps. Confidence levels of the branching points were determined using 1000 bootstrap replicates.

\section{Comparative plasmid sequence (plasmidomic) analysis}

The eight native plasmids sequenced in this study were aligned using "MAUVE: Multiple Genome Alignment" to analyze the plasmids synteny [80]. In addition, MAUVE allows efficient construction of multiple alignments in the presence of large-scale evolutionary events such as rearrangements and inversions. The eight native plasmids were compared using the Venn diagram analysis software "jvenn" [81] in order to define the core genes.

In addition, the pPg2708 plasmid was analyzed in order to characterize the promoters of the rulAB genes that are not forming an operon in this plasmid. The promoter prediction was performed using BPROM from SoftBerry (http://www.softberry.com, Mount Kisco, NY, USA). The Shine-Dalgarno (SD) sequences were also defined according to Ma et al. [82]. The search of the hrp box promoter sequences for the different type III effectors harbored by the pPg2708 plasmid was performed based on the consensus sequence 5'-GGAACC-N15-16CCACNNA-3' [83].

\section{Unraveling putative encoding-Type III effector genes}

All the hypothetical proteins found in each native plasmid sequenced in this study, were analyzed to determine their possible role in virulence as effector proteins of the T3SS. Signal peptide cleavage sites were predicted using the SignalP 4.1 server $[84,85]$ and Sigcleave whose are accessible at http://www.cbs.dtu.dk/services/SignalP/ and http://emboss.bioinformatics.nl/cgi-bin/emboss/sigcleave respectively. Prediction of transmembrane helices domains in proteins was performed using the TMHMM Server v. 2.0 [86], which is accessible at http:// www.cbs.dtu.dk/services/TMHMM/. Finally, a prediction of secreted proteins based on amino acid sequences was carried out using Effective T3 [87], which is accessible at http://www.effectors.org/news/new-effectivet3model. Two different modules were used: a standard classification module that comprises effectors of Escherichia coli, Salmonella, Chlamydia, Yersinia, and Pseudomonas (opportunistic human and animal pathogens), and plant classification module that comprises effector sequences from $P$. syringae (plant pathogen). In both cases, a cut-off value of 0.9 in a sensitive setting was selected to carry out the analysis.

\section{Nucleotide sequence accession numbers}

The complete plasmid sequences obtained in this study are deposited at NCBI under the accession numbers: KY362366 (pPt0893-29), KY362367 (pPg2708), KY362368 (pPs0081), KY362369 (pPs 6-9), KY362370 (pPs0158), KY362371 (pPs1029), KY362372 (pPs0170) and KY362373 (pPs7B44). GenBank accession numbers for sequences of the chromosomal gene $\operatorname{gyrB}$ are as follows: DQ072672.1 to DQ072693.1, AB016387.1, CM001986.1, JX867861.1, JX867909.1， JX867863.1， JX867862.1， CM001834.1， AB016323.1, CP000058.1, AY610777.1, AY610778.1, NC_004578.1, NZ_CP011972.2 and NZ_CP006857.1. GenBank accession numbers for sequence of the chromosomal gene rpoD are as follows: DQ072694.1 to DQ072715.1, AB016388.1, CM001986.1, JX867782.1, JX867829.1， JX867784.1， JX867783.1， CM001834.1， 
AB016324.1, CP000058.1, AY610897.1, AY610898.1, NC_004578.1, NZ_CP011972.2 and NZ_CP006857.1. GenBank accession numbers for sequence of the plasmid replication gene repA are as follows: DQ072652 to DQ072671, AY768793.1 to AY768802.1, AY768804.1 to AY768807.1, NC_004632.1, NC_004633.1, CP000059.1, CP000060.1, NC_019265.1, NC_019266.1, NC_019292.1, NC_002759.1, NC_005918.1, NC_005919.1, NC 005205.1, NZ_CP011973.1, NZ_CM001987.1, NZ_ CP006855.1, NZ_CP006856.1 and including the rep $A$ sequences of the 8 plasmids sequenced in this study.

\section{Additional files}

Additional file 1: Table S1. Primers used in this study. (PDF 14 kb)

Additional file 2: Figure S1. Polymerase chain reaction to test the closed plasmids DNA sequences. Amplicons of the expected size obtained using specific primers designed on the final and the beginning of the raw plasmid DNA sequences. M: molecular weight marker HyperLadder 1Kb (Bioline). GD: PCR carried out using Genomic DNA; PD: PCR carried out using Plasmid DNA. (PDF $78 \mathrm{~kb}$ )

Additional file 3: Table S2-S9. Predicted ORF's in the different plasmids sequenced in this study. (PDF $488 \mathrm{~kb}$ )

Additional file 4: Figure S2. Plasmid sequences alignment. Pairwise alignment between the 8 different plasmid sequenced in this study, was carried out using the MAUVE software. Colored blocks: plasmid sequences that aligned to other plasmid parts, being presumably homologous without no internal rearrangement. White regions: probably specific sequence elements to a particular plasmid. Blocks below the central line of each plasmid represent sequences that aligned in the reverse complement orientation. (PDF $247 \mathrm{~kb}$ )

Additional file 5: Figure S3. Type IV secretion systems analysis. a The type IV MPF Tecretion system is normally encoded by 11 virB genes and the virD4 gene. Graphical map for the type IV MPF genes from the plasmids sequenced in this study, including the type IV $\mathrm{MPF}_{\mathrm{T}}$ of the PPSR1 plasmid from Pseudomonas syringae pv. syringae A2. b Schematic representation of the type IV MPF, secretion system genes from pPt0893-29 plasmid sequenced in this study, including the type IV MPF, from pPtDC3000A from Pseudomonas syringae pv. tomato for their comparison. Genes with similar functions were drawn with similar colors. (PDF $33 \mathrm{~kb}$ )

Additional file 6: Figure S4. Plasmid map graphical comparison of pPs0170 and pPs7B44. Green dotted lines and grey box represent a sub part from the genomic island Gl6 from Pseudomonas syringae pv. syringae B728a forming part of both plasmids. Purple arrows: Arsenic resistance genes. (PDF $112 \mathrm{~kb}$ )

\section{Abbreviations}

CsCl-EtBr: Cesium chloride-ethidium bromide; PCR: Polymerase chain reaction; PFP's: PPT23A-family plasmids; pv.: Pathovar; T3SS: Type III secretion system

\section{Acknowledgements}

The authors would like to thank Professor Jesús Murillo from the Public University of Navarra, Spain, for his help to develop and set up the plasmid purification $\mathrm{CsCl}-\mathrm{EtBr}$ gradient protocol.

\section{Funding}

This work has been supported by grants from CICE-Junta de Andalucía, Proyecto de Excelencia (P07-AGR-02471; P12-AGR-1473) cofinanced by FEDER (EU), and by Michigan State University AgBioResearch. "Research Own Plan" of the University of Málaga funded a short research stay by J.A. Gutiérrez-Barranquero at Michigan State University (USA), in the Department of Plant, Soil and Microbial Sciences.

\section{Availability of data and materials}

The PPT23A plasmids sequenced in this study are deposited at NCBI under the accession numbers KY362366, KY362367, KY362368, KY362369, KY362370, KY362371, KY362372 and KY362373. In addition, all nucleotide sequences used for phylogenetic analysis are deposited at NCBI as well (accession numbers are included in Methods, under the "Nucleotide sequence accession numbers" section). The $P$. syringae strains harboring these plasmids are available from the corresponding author on reasonable request.

\section{Authors' contributions}

JAGB, FMC, ADV and GWS designed the main aims of this work. JAGB performed plasmid DNA isolation and purification, and the different molecular biology techniques used in this study. JAGB and FMC conducted the different bioinformatic approaches to carry out the comparative genomics. JAGB and GWS wrote the manuscript. FMC, ADV and GWS provided guidance in the drafting of the manuscript. All authors read, corrected and approved the final manuscript.

\section{Competing interests}

The authors declare that they have no competing interests.

\section{Consent for publication}

Not applicable.

Ethics approval and consent to participate

Not applicable.

\section{Publisher's Note}

Springer Nature remains neutral with regard to jurisdictional claims in published maps and institutional affiliations.

\section{Author details}

${ }^{1}$ Instituto de Hortofruticultura Subtropical y Mediterránea La Mayora (IHSM-UMA-CSIC), Departamento de Microbiología, Facultad de Ciencias, Universidad de Málaga, Málaga, Spain. ²Department of Plant, Soil, and Microbial Sciences, Michigan State University, East Lansing, MI 48824, USA.

Received: 17 January 2017 Accepted: 3 May 2017

Published online: 10 May 2017

\section{References}

1. Young JM. Taxonomy of Pseudomonas syringae. J Plant Pathol. 2010;92:S5-14

2. Sarkar SF, Guttman DS. Evolution of the core genome of Pseudomonas syringae, a highly clonal, endemic plant pathogen. Appl Environ Microbiol. 2004;70:1999-2012.

3. Sarris PF, Trantas EA, Baltrus DA, Bull CT, Wechter WP, Yan S, et al. Comparative genomics of multiple strains of Pseudomonas cannabina pv. alisalensis, a potential model pathogen of both monocots and dicots. PLoS ONE. 2013;8:e59366.

4. Lindeberg M, Cunnac S, Collmer A. The evolution of Pseudomonas syringae host specificity and type III effector repertoires. Mol Plant Pathol. 2009;10:767-75.

5. Baltrus DA, Nishimura MT, Romanchuk A, Chang JH, Mukhtar MS, Cherkis K, et al. Dynamic evolution of pathogenicity revealed by sequencing and comparative genomics of 19 Pseudomonas syringae isolates. PLoS Pathog. 2011;7:e1002132.

6. Lindeberg M, Cunnac S, Collmer A. Pseudomonas syringae type III effector repertoires: last words in endless arguments. Trends Microbiol. 2012;20:199-208.

7. Rodríguez-Herva JJ, González-Melendi P, Cuartas-Lanza R, Antúnez-Lamas M, Río-Alvarez I, Li Z, et al. A bacterial cysteine protease effector protein interferes with photosynthesis to suppress plant innate immune responses. Cell Microbiol. 2012;14:669-81.

8. Block A, Toru TY, Elowsky CG, Zhang C, Steinbrenner J, Beynon J, et al. The Pseudomonas syringae type III effector HopD1 suppresses effector-triggered immunity, localizes to the endoplasmic reticulum, and targets the Arabidopsis transcription factor NTL9. New Phytol. 2014;201:1358-70.

9. Kim JF, Charkowski AO, Alfano JR, Collmer A, Beer SV. Sequences related to transposable elements and bacteriophages flank avirulence genes of Pseudomonas syringae. Mol Plant-Microbe Interact. 1998;11:1247-52. 
10. McCann HC, Guttman DS. Evolution of the type III secretion system and its effectors in plant-microbe interactions. New Phytol. 2008;177:33-47.

11. Lindeberg M. Genome-Enabled perspectives on the composition, evolution, and expression of virulence determinants in bacterial plant pathogens. Annu Rev Phytopathol. 2012;50:111-32.

12. Norman A, Hansen LH, Sørensen SJ. Conjugative plasmids: vessels of the communal gene pool. Philos Trans R Soc London B. 2009;364:2275-89.

13. Campbell A. Evolutionary significance of accessory DNA elements in bacteria. Ann Rev Microbiol. 1981;35:55-83.

14. Medini D, Donati C, Tettelin H, Masignani V, Rappouli R. The microbial pangenome. Curr Opin Genet Dev. 2005;15:589-94.

15. Sundin GW. Genomic insights into the contribution of phytopathogenic bacterial plasmids to the evolutionary history of their hosts. Annu Rev Phytopathol. 2007:45:129-51.

16. Jannière L, Niaudet B, Ehrlich SD. Repeated DNA sequences recombine 1,000 times more frequently in a plasmid than in the chromosome of Bacillus subtilis. Basic Life Sci. 1985:30:93-103.

17. Arber W. Elements in microbial evolution. J Mol Evol. 1991;33:4-12.

18. Wiedenbeck J, Cohan FM. Origins of bacterial diversity through horizontal genetic transfer and adaptation to new ecological niches. FEMS Microbiol Rev. 2011;35:957-76.

19. Sesma A, Sundin GW, Murillo J. Closely related plasmid replicons coexisting in the phytopathogen Pseudomonas syringae show a mosaic organization of the replication region and altered incompatibility behavior. Appl Environ Microbiol. 1998:64:3948-53.

20. Sesma A, Murillo J, Sundin GW. Phylogeny of the replication regions of PPT23A-like plasmids from Pseudomonas syringae. Microbiology. 2000;146(10):2375-84

21. Zhao Y, Ma Z, Sundin GW. Comparative genomic analysis of the PPT23A plasmid family of Pseudomonas syringae. J Bacteriol. 2005;187:2113-26.

22. Guglielmini J, Neron B, Abby SS, Garcillán-Barcia MP, de la Cruz F, Rocha EPC. Key components of the eight classes of type IV secretion systems involved in bacterial conjugation or protein secretion. Nucleic Acid Res. 2014:42:5715-27.

23. Sundin GW, Mayfield CT, Zhao Y, Gunasekera TS, Foster GL, Ullrich MS. Complete nucleotide sequence and analysis of pPSR1 (72,601 bp), a PPT23A-family plasmid from Pseudomonas syringae pv. syringae A2. Mol Genet Genom. 2004;270:462-76.

24. Pérez-Martínez I, Zhao Y, Murillo J, Sundin GW, Ramos C. Global genomic analysis of Pseudomonas savastanoi plasmids. J Bacteriol. 2008;190(2):625-35.

25. Bardaji L, Pérez-Martínez I, Rodríguez-Moreno L, Rodríguez-Palenzuela P, Sundin GW, Ramos C, et al. Sequence and role in virulence of the three plasmid complement of the model tumor-inducing bacterium Pseudomonas savastanoi pv. savastanoi NCPPB 3335. PLoS ONE. 2012;6(10):e25705.

26. Ma Z, Smith JJ, Zhao Y, Jackson RW, Arnold DL, Murillo J, et al. Phylogenetic analysis of the PPT23A plasmid family of Pseudomonas syringae. Appl Environ Microbiol. 2007;73:1287-95.

27. Sundin GW, Bender CL. Molecular analysis of closely related copper- and streptomycin- resistance plasmids in Pseudomonas syringae pv syringae. Plasmid. 1996;107:98-107.

28. Cazorla FM, Arrebola E, Sesma A, Pérez-García A, Codina JC, Murillo J, et al. Copper resistance in Pseudomonas syringae strains isolated from mango is encoded mainly by plasmids. Phytopathology. 2002;92:909-16.

29. Gutiérrez-Barranquero JA, de Vicente A, Carrión VJ, Sundin GW, Cazorla FM. Recruitment and rearrangement of three different genetic determinants into a conjugative plasmid increase copper resistance in Pseudomonas syringae. Appl Environ Microbiol. 2013;79:1028-33.

30. Buell CR, Joardar V, Lindeberg M, Selengut J, Paulsen IT, Gwinn ML, et al. The complete genome sequence of the Arabidopsis and tomato pathogen Pseudomonas syringae pv. tomato DC3000. Proc Natl Acad Sci U S A. 2003;100:10181-6.

31. Rohmer L, Kjemtrup S, Marchesini P, Dangl JL. Nucleotide sequence, functional characterization and evolution of pFKN, a virulence plasmid in Pseudomonas syringae pathovar maculicola. Mol Microbiol. 2003:47:1545-62.

32. Stavrinides J, Guttman DS. Nucleotide sequence and evolution of the fiveplasmid complement of the phytopathogen Pseudomonas syringae pv. maculicola ES4326. J Bacteriol. 2004;186:5101-15.

33. Joardar V, Lindeberg M, Jackson RW, Selengut J, Dodson R, Brinkac LM, et al Whole-genome sequence analysis of Pseudomonas syringae pv. phaseolicola 1448A reveals divergence among pathovars in genes involved in virulence and transposition. J Bacteriol. 2005;187:6488-98.
34. Dudnik A, Dudler R. High-quality draft genome sequence of Pseudomonas syringae pv. syringae strain SM, isolated from wheat. Genome Announc 2013;1:e00610-3.

35. Ravindran A, Jalan N, Yuan JS, Wang N, Gross DC. Comparative genomics of Pseudomonas syringae pv. syringae strains B301D and HS191 and insights into intrapathovar traits associated with plant pathogenesis. Microbiologyopen. 2015;4:553-73.

36. Qi M, Wang D, Bradley CA, Zhao Y. Genome sequence analyses of Pseudomonas savastanoi pv glycinea and subtractive hybridizationbased comparative genomics with nine pseudomonads. PLoS ONE. 2011:6:e16451.

37. Studholme DJ, Glover RH, Boonham N. Application of high-throughput DNA sequencing in phytopathology. Annu Rev Phytopathol. 2011;49:87-105.

38. McCann HC, Rikkerink EHA, Bertels F, Fiers M, Lu A, Rees-George J, et al. Genomic analysis of the kiwifruit pathogen Pseudomonas syringae pv actinidiae provides insight into the origins of an emergent plant disease. PLoS Pathog. 2013;9:e1003503.

39. Thakur S, Weir BS, Guttmann DS. Phytopathogen genome announcement: draft genome sequences of 62 Pseudomonas syringae type and pathotype strains. Mol Plant-Microbe Interact. 2016;29:243-6.

40. Vivian A, Murillo J, Jackson RW. The roles of plasmids in phytopathogenic bacteria: mobile arsenals? Microbiology. 2001;147(4):763-80

41. Murillo J, Keen NT. Two native plasmids of Pseudomonas syringae pathovar tomato strain PT23 share a large amount of repeated DNA, including replication sequences. Mol Microbiol. 1994;12(6):941-50.

42. Sundin GW, Kidambi SP, Ullrich M, Bender CL. Resistance to ultraviolet light in Pseudomonas syringae: sequence and functional analysis of the plasmidencoded rulAB genes. Gene. 1996;177(1-2):77-81.

43. Sundin GW, Murillo J. Functional analysis of the Pseudomonas syringae rulAB determinant in tolerance to ultraviolet B (290 to $320 \mathrm{~nm}$ ) radiation and distribution of rul $A B$ among $P$. syringae pathovars. Environ Microbiol. 1999:1(1):75-87

44. Kim JJ, Sundin GW. Regulation of the rulAB mutagenic DNA repair operon of Pseudomonas syringae by UV-B (290 to 320 nanometers) radiation and analysis of rulAB-mediated mutability in vitro and in planta. J Bacteriol. 2000:182(21):6137-44.

45. Sundin GW, Bender CL. Ecological and genetic analysis of copper and streptomycin resistance in Pseudomonas syringae pv. syringae. Appl Environ Microbiol. 1993;59(4):1018-24.

46. Cascales E, Christie PJ. The versatile bacterial type IV secretion systems. Nat Rev Microbiol. 2003;1(2):137-49.

47. Lichter A, Barash I, Valinsky L, Manulis S. The genes involved in cytokinin biosynthesis in Erwinia herbicola pv. gypsophilae: characterization and role in gall formation. J Bacteriol. 1995;177(15):4457-65.

48. Dow JM, Fouhy Y, Lucey JF, Ryan RP. The HD-GYP domain, cyclic di-GMP signaling, and bacterial virulence to plants. Mol Plant-Microbe Interact. 2006:19:1378-84

49. Edmunds AC, Castiblanco LF, Sundin GW, Waters CM. Cyclic di-GMP modulates the disease progression of Erwinia amylovora. J Bacteriol. 2013;195:2155-65

50. Aragon IM, Perez-Mendoza D, Moscoso JA, Faure E, Guery B, Gallegos MT, et al. Diguanylate cyclase DgcP is involved in plant and human Pseudomonas spp. infections. Environ Microbiol. 2015;17:4332-51.

51. Wei $C$, Jiang WD, Zhao MR, Ling JJ, Zeng $X$, Deng J, et al. A systematic analysis of the role of GGDEF-EAL domain proteins in virulence and motility in Xanthomonas oryzae pv oryzicola. Sci Rep. 2016;6:23769.

52. Bardaji L, Anorga M, Ruiz-Maso JA, del Solar G, Murillo J. Plasmid replicons from Pseudomonas are natural chimeras of functional, exchangeable modules. Front Microbiol. 2017:8:190.

53. Feil H, Feil WS, Chain P, Larimer F, DiBartolo G, Copeland A, et al. Comparison of the complete genome sequences of Pseudomonas syringae pv. syringae B728a and pv. tomato DC3000. Proc Natl Acad Sci U S A. 2005;102(31):11064-9.

54. Arnold DL, Jackson RW, Vivian A. Evidence for the mobility of an avirulence gene, avrPpiA1, between the chromosome and plasmids of races of Pseudomonas syringae pv. pisi. Mol Plant Pathol. 2000;1(3):195-9.

55. Rhodes G, Bosma H, Studholme D, Arnold DL, Jackson RW, Pickup RW. The rulB gene of plasmid pWWO is a hotspot for the site-specific insertion of integron-like elements found in the chromosomes of environmental Pseudomonas fluorescens group bacteria. Environ Microbiol. 2014;16(8):2374-88 
56. Pitman AR, Jackson RW, Mansfield JW, Kaitell V, Thwaites R, Arnold DL. Exposure to host resistance mechanisms drives evolution of bacterial virulence in plants. Curr Biol. 2005;15(24):2230-5.

57. Curiale MS, Mills D. Integration and partial excision of a cryptic plasmid in Pseudomonas syringae pv. phaseolicola. J Bacteriol. 1982;152(2):797-802.

58. Szabo L, Mills D. Integration and excision of pMC7105 in Pseudomonas syringae pv. phaseolicola - involvement of repetitive sequences. J Bacteriol. 1984;157(3):821-927.

59. Neale HC, Slater RT, Mayne L-M, Manoharan B, Arnold DL. In planta induced changes in the native plasmid profile of Pseudomonas syringae pathovar phaseolicola strain 1302A. Plasmid. 2013;70:420-4.

60. Arnold DL, Jackson RW, Waterfield NR, Mansfield JW. Evolution of microbial virulence: the benefits of stress. Trends Genet. 2007:23(6):293-300.

61. Harrison E, Brockhurst MA. Plasmid-mediated horizontal gene transfer is a coevolutionary process. Trends Microbiol. 2012;20(6):262-7.

62. San Millan A, Pena-Miller R, Toll-Riera M, Halbert ZV, McLean AR, Cooper BS, MacLean RC. Positive selection and compensatory adaptation interact to stabilize non-transmissible plasmids. Nat Commun. 2014;5:5208.

63. Thomas CM. Paradigms of plasmid organization. Mol Microbiol. 2000;37(3):485-91.

64. Sundin GW, Bender CL. Relative fitness in vitro and in planta of Pseudomonas syringae strains containing copper and streptomycin resistance plasmids. Can J Microbiol. 1994:40(4):279-85.

65. da Silva ACR, Ferro JA, Reinach FC, Farah CS, Furlan LR, Quaggio RB, Monteiro-Vitorello CB, Van Sluys MA, Almeida NF, Alves LMC, et al. Comparison of the genomes of two Xanthomonas pathogens with differing host specificities. Nature. 2002;417:459-63.

66. Maxson-Stein K, McGhee GC, Smith JJ, Jones AL, Sundin GW. Genetic analysis of a pathogenic Erwinia sp. isolated from pear in Japan. Phytopathology. 2003:93(11):1393-9.

67. Pothier JF, Vorholter F-J, Blom J, Goesmann A, Puhler A, Smiths THM, Duffy B. The ubiquitous plasmid pXap41 in the invasive phytopathogen Xanthomonas arboricola pv. pruni: complete sequence and comparative genomic analysis. FEMS Microbiol Lett. 2011;323:52-60.

68. Niu X-N, Wei Z-Q, Zou H-F, Xie G-G, Wu F, Li K-J, Jiang W, Tang J-L, He Y-Q. Complete sequence and detailed analysis of the first indigenous plasmid from Xanthomonas oryzae pv oryzicola. BMC Microbiol. 2015;15:233.

69. Stockwell VO, Davis II EW, Carey A, Shaffer BT, Mavrodi DV, Hassan KA Hockett K, Thomashow LS, Paulsen IT, Loper JE. pA506, a conjugative plasmid of the plant epiphyte Pseudomonas fluorescens A506. Appl Environ Microbiol. 2013;79(17):5272-82.

70. Tett A, Spiers AJ, Crossman LC, Ager D, Ciric L, Dow JM, Fry JC, Harris D, Lilley A, Oliver A, et al. Sequence-based analysis of pQBR103: as representative of a unique, transfer-proficient mega plasmid resident in the microbial community of sugar beet. ISME J. 2007;1(4):331-40.

71. Zhou C, Yang Y, Jong AY. Miniprep in ten minutes. Biotechniques. 1990:8:172-3.

72. Sambrook J, Russel DW. Molecular cloning: a laboratory manual. $3^{\text {rd }}$ ed. Cold Spring Harbor, NY: Cold Spring Harbor Laboratory Press; 2001.

73. Murillo J, Shen H, Gerhold D, Sharma AK, Cooksey DA, Keen NT. Characterization of pPT23B, the plasmid involved in syringolide production by Pseudomonas syringae pv. tomato PT23. Plasmid. 1994;31:275-87.

74. Martinéz-García PM, Rodríguez-Palenzuela P, Arrebola A, Carrión VJ, Gutiérrez-Barranquero JA, Pérez-García A, et al. Bioinformatics analysis of the complete genome sequence of the mango tree pathogen Pseudomonas syringae pv. syringae UMAF0158 reveals traits relevant to virulence and epiphytic lifestyle. PLoS ONE. 2015;10:e0136101.

75. Tatusova TA, Madden TL. Blast 2 sequences, a new tool for comparing protein and nucleotide sequences. FEMS Microbiol Lett. 1999;174:247-50.

76. Overbeek R, Olson R, Pusch GD, Olsen GJ, Davis JJ, Disz T, et al. The SEED and the Rapid Annotation of microbial genomes using Subsystems Technology (RAST). Nucleic Acids Res. 2014;42:206-14.

77. Altschul SF, Madden TL, Schaffer AA, Zhang J, Zhang Z, Miller W, Lipman DJ. Gapped BLAST and PSI-BLAST: a new generation of protein database search programs. Nucleic Acids Res. 1997;25:3389-402.

78. Larkin MA, Blackshields G, Brown NP, Chenna R, McGettigan PA, McWilliam H, et al. ClustalW and ClustalX version 2. Bioinformatics. 2007;23:2947-8.

79. Tamura K, Peterson D, Peterson N, Stecher G, Nei M, Kumar S. MEGA5: molecular evolutionary genetics analysis using maximum likelihood, evolutionary distance, and maximum parsimony methods. Mol Biol Evol. 2011;28:2731-9
80. Darling ACE, Mau B, Blatter FR, Perna NT. Mauve: multiple alignment of conserved genomic sequence with rearrangements. Genome Res. 2004;14:1394-403.

81. Bardou P, Mariette J, Escudie F, Djemiel C, Klopp C. Jvenn: an interactive Venn diagram viewer. BMC Bioinform. 2014;15:293.

82. Ma J, Campbell A, Karlin S. Correlations between Shine-Dalgarno sequences and gene features such as predicted expression levels and operon structures. J Bacteriol. 2002;184:5733-45.

83. Nissan G, Manulis S, Weinthal DM, Sessa G, Barash I. Analysis of promoters recognized by $\mathrm{HrpL}$, an alternative sigma-factor protein from Pantoea agglomerans pv. gypsophilae. Mol Plant-Microbe Interact. 2005;18:634-43.

84. Nielsen $\mathrm{H}$, Engelbrecht J, Brunak S, von Heijne G. Identification of prokaryotic and eukaryotic signal peptides and prediction of their cleavage sites. Protein Eng. 1997;10:1-6.

85. Petersen TN, Brunak S, von Heijne G, Nielsen H. SignalP 4.0: discriminating signal peptides from transmembrane regions. Nat Methods. 2011;8:785-6.

86. Krogh A, Larsson B, von Heijne G, Sonnhammer EL. Predicting transmembrane protein topology with a hidden Markov model: application to complete genomes. J Mol Biol. 2001;305:567-80.

87. Jehl MA, Arnold R, Rattei T. Effective-a database of predicted secreted bacterial proteins. Nucleic Acids Res. 2011;39:591-5.

88. Cazorla FM, Codina JC, Abad C, Arrebola E, Tores JA, Murillo J, Perez-Garcia A de Vicente A. 62-kb plasmids harboring rulAB homologues confer UV-tolerance and epiphytic fitness to Pseudomonas syringae pv. syringae mango isolates. Microb Ecol. 2008:56:283-91.

89. Renick L, Cogal AG, Sundin GW. Phenotypic and genetic analysis of epiphytic Pseudomonas syringae populations from sweet cherry in Michigan. Plant Dis. 2008:92:372-8.

\section{Submit your next manuscript to BioMed Central and we will help you at every step:}

- We accept pre-submission inquiries

- Our selector tool helps you to find the most relevant journal

- We provide round the clock customer support

- Convenient online submission

- Thorough peer review

- Inclusion in PubMed and all major indexing services

- Maximum visibility for your research

Submit your manuscript at www.biomedcentral.com/submit

) Biomed Central 